\title{
Los efectos de los medios de comunicación de masas
}

\section{Víctor Hernández Santaolalla • 2018}

Barcelona: UOC $\bullet 200$ páginas

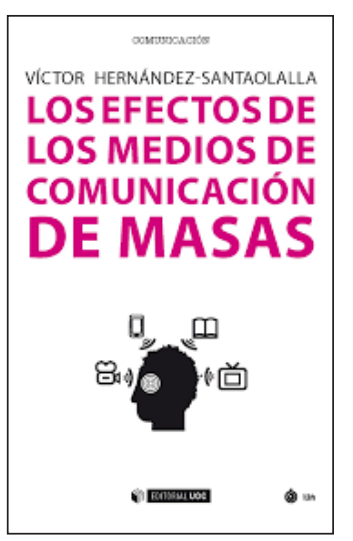

En el último capítulo del libro Los efectos de los medios de comunicación de masas (2018), de Víctor Hernández-Santaolalla, se cuestiona el desarrollo investigativo de la comunicación, cuáles son los efectos de las plataformas sociales en los usuarios. Efectos e influencia son categorías que delinearon el sendero investigativo, inclusive, en las tesis de la zona latinoamericana durante varias décadas.

Hay publicaciones relevantes que no necesariamente se enfocan en temáticas inéditas 0 "actuales". Más bien, algunos textos trascienden como un material de trabajo pedagógico para entender la disciplina comunicacional de manera secuencial y sistemática en torno a las teorías clásicas. Es el caso del libro de Hernández-Santaolalla cuyo horizonte investigativo, sin embargo, eclipsa, parcialmente, asuntos como la comunicación digital y el imperio de los algoritmos.

Al parecer, los esfuerzos reflexivos de los comunicadores y académicos no se han decantado totalmente por la dinámica del universo de la internet 0 , en tensiones más específicas, de las redes sociales en estos tiempos de vértigo digital, en la zona Ibérica. También parecería que el debate sobre los medios de comunicación de masas y sus efectos e influencia ha quedado zanjada. Para Hernández-Santaolalla, cobra vigencia la teoría de los efectos y la influencia hoy por hoy.

Sobre lo anterior, Santaolalla esgrime un argumento: repensar la influencia de los medios, en términos no solo conductuales sino cognitivos. En realidad, lo mediático, además, es decisivo en su conexión con la sociedad. Acto seguido, Santaolalla ilustra con la televisión, medio de masas, y su relación con la violencia. A este medio no se le puede indilgar la generación de violencia en la sociedad. Dicha problemática es multidimensional.

La evolución de los media devino en un enjambre de plataformas con nuevas especies digitales que son analizadas a partir de packs teóricos o enfoques comunicacionales clásicos. Es decir, se intenta aplicar ciertas cuestiones teóricas de la comunicación tradicional para revelar asuntos actuales. De esta manera, se explica desde la espiral del silencio, el entramado digital, cuando, por ejemplo, los usuarios asumen una postura silente y, abrumados por el miedo al aislamiento, distinta frente a las opiniones de la mayoría del grupo o red.

Retornemos al capítulo inicial, en el cual Santaolalla retrotrae de manera sistemática las tradicionales teorías y modelos de la comunicación. Le importa sobremanera aproximarse a una conceptualización primordial del efecto de la comunicación. De ahí se bifurcan los efectos. A esto se suma una fórmula significativa que conlleva la persuasión o la posibilidad de forjar influjos en el comportamiento de los perceptores. 
El capítulo más nutrido da cuenta de las fórmulas de la comunicación. Incluso se incorporan las coordenadas que engloban a la Escuela de Chicago, la aguja hipodérmica y la fórmula de Lasswell, la era de los efectos ilimitados, sleeper effect, la teoría de la información o matemática. Sin embargo, el estructuralismo y los modos de analizar los discursos, que se posicionaron en la zona latinoamericana, son soslayados en este punto.

De igual manera, se pone el foco en la contundencia de las premisas de McLuhan y, entre otras cosas, en su determinismo tecnológico. Hasta ahora, sujetos teóricos latinoamericanos también hurgan en el legado con ingentes esfuerzos en pos de desencriptar sus propuestas. Así, la obsolescencia es rasgo fundamental, ente otros, de los medios y, además, uno de los elementos centrales para la mediaevolución.

En los capítulos medulares se incorporan libros emblema como el de MacCombs (2004) La Agenda Setting que dejaron su impronta a nivel periodístico y a nivel de investigación. McCombs evidencia cómo se diseña, a veces de manera compleja, la agenda de los medios tradicionales que es permeable y, al mismo tiempo, influencia en lo que se denomina la opinión pública. Devela cómo las diversas organizaciones que orbitan, mediante agendas, presionan/accionan conductas en los ciudadanos.

Estableciendo la agenda planteó en los primeros años del siglo XXI una pregunta crucial, respaldado por estudios estadounidenses: ¿quién influencia a quién: los medios al público; el público a los medios?. En definitiva, MacCombs dirime esta interrogante: los medios influyen al público. De igual manera, existe una dimensión sicológica, en el sentido de que los medios y su influjo pueden modificar actitudes y comportamientos.

Existen múltiples elementos que construyen la agenda: "se ha esbozado una respuesta a quién fija la agenda mediática a partir de la consideración de tres elementos: las principales fuentes que suministran la información para las noticias, otras organizaciones informativas y las normas y tradiciones del periodismo" (223).

Los estudios culturales vinculados a la comunicación se instalan también en estas páginas. De hecho, la cultura es, definitivamente, una cuestión prevalente en el entramado social. La Escuela de Birmingham fue un enclave y referente en las indagaciones de la cultura. Su contingente teórico se trasladó y confrontó a pensadores quienes trasladaron sus marcos teóricos para identificar disputas hegemónicas más específicas en entornos culturales latinoamericanos.

En el último tramo del texto, el autor no distingue entre lo mediático, las redes sociales y los sistemas operativos. Aquí se limita a entender a dichas redes en tanto nuevas tecnologías. Cabe enfatizar que lo mediático tiene distinta organicidad a las redes sociales virtuales, que es restringido hablar de la internet como un nuevo medio. Consecuentemente, la comunicación digital se plantea inabarcable y desafiante para los investigadores sociales.

Noha Puma • Correo: noha7puma@gmail.com 